\title{
Transdiagnostic comparison of visual working memory capacity in bipolar disorder and schizophrenia
}

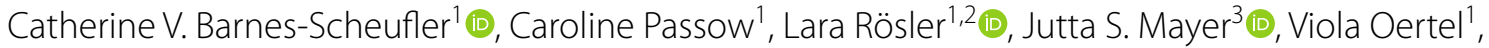

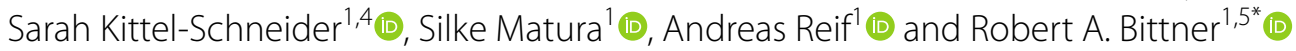

\begin{abstract}
Background: Impaired working memory is a core cognitive deficit in both bipolar disorder and schizophrenia. Its study might yield crucial insights into the underpinnings of both disorders on the cognitive and neurophysiological level. Visual working memory capacity is a particularly promising construct for such translational studies. However, it has not yet been investigated across the full spectrum of both disorders. The aim of our study was to compare the degree of reductions of visual working memory capacity in patients with bipolar disorder (PBD) and patients with schizophrenia (PSZ) using a paradigm well established in cognitive neuroscience.
\end{abstract}

Methods: 62 PBD, 64 PSZ, and 70 healthy controls (HC) completed a canonical visual change detection task. Participants had to encode the color of four circles and indicate after a short delay whether the color of one of the circles had changed or not. We estimated working memory capacity using Pashler's K.

Results: Working memory capacity was significantly reduced in both PBD and PSZ compared to HC. We observed a small effect size $(r=.202)$ for the difference between HC and PBD and a medium effect size $(r=.370)$ for the difference between HC and PSZ. Working memory capacity in PSZ was also significantly reduced compared to PBD with a small effect size $(r=$.201). Thus, PBD showed an intermediate level of impairment.

Conclusions: These findings provide evidence for a gradient of reduced working memory capacity in bipolar disorder and schizophrenia, with PSZ showing the strongest degree of impairment. This underscores the importance of disturbed information processing for both bipolar disorder and schizophrenia. Our results are compatible with the cognitive manifestation of a neurodevelopmental gradient affecting bipolar disorder to a lesser degree than schizophrenia. They also highlight the relevance of visual working memory capacity for the development of both behaviorand brain-based transdiagnostic biomarkers.

Keywords: Bipolar disorder, Schizophrenia, Cognitive dysfunction, Working memory capacity, Attention

\section{Background}

Cognitive impairment across a wide range of domains is a central common characteristic of both bipolar disorder and schizophrenia (Martínez-Arán et al. 2004; Kahn

\footnotetext{
*Correspondence: robert.bittner@med.uni-frankfurt.de

1 Department of Psychiatry, Psychosomatic Medicine, and Psychotherapy, University Hospital Frankfurt, Goethe University, Heinrich-Hoffmann-Str. 10, 60528 Frankfurt am Main, Germany

Full list of author information is available at the end of the article
}

and Keefe 2013; Vöhringer et al. 2013; Bora and Pantelis 2015; Miskowiak et al. 2018). Consequently, both have been conceptualized as information processing disorders (Kahn and Keefe 2013; Bortolato et al. 2015). This paradigm supports the notion that transdiagnostic comparisons of crucial cognitive constructs are a central element of translational strategies to establish a psychiatric nosology based on the assessment of cognitive dimensions and the brain networks which give rise to them 
(Cuthbert 2014; Insel 2014). Ultimately, this should lead to the identification of neurobiologically distinct biotypes across diagnostic boundaries (Clementz et al. 2016) and the development of behavioral and brain-based biomarkers (Oertel-Knöchel et al. 2011). Furthermore, it might also facilitate a better understanding of the neurophysiological disturbances underlying impaired information processing and the development of more effective procognitive interventions.

The need for transdiagnostic studies is underscored by the substantial phenomenological and pathophysiological overlap of bipolar disorder and schizophrenia (Ivleva et al. 2010; Pearlson 2015). They have the highest amount of shared heritability among neuropsychiatric disorders (Anttila et al. 2018; Lee et al. 2019). Both are also regarded to different degrees as neurodevelopmental disorders (Bortolato et al. 2015; Pearlson 2015), possibly forming a neurodevelopmental continuum (Owen and O'Donovan 2017). This implies that risk factors disturbing brain development and cognition play a larger role in schizophrenia than in bipolar disorder. Interestingly, most studies have reported a gradient of cognitive impairment with patients with schizophrenia generally more affected than patients with bipolar disorder (Goldberg 1999; Schretlen et al. 2007; Ivleva et al. 2010; Lewandowski et al. 2011; Hill et al. 2013; Reilly and Sweeney 2014).

Working memory is universally regarded as a central cognitive domain for transdiagnostic studies of impaired information processing (Insel et al. 2010). It is a crucial determinant of essential cognitive functions such as language comprehension and reasoning (Baddeley 1992), as well as an important mediator of cognitive development and learning (Baddeley and Hitch 1974; Cowan 2014). Working memory dysfunction is a central cognitive deficit in both bipolar disorder and schizophrenia (Glahn et al. 2006; Barch and Smith 2008). It has been reported in a large number of behavioral studies in schizophrenia across all stages of illness (Lee and Park 2005; Barch and Smith 2008; Luck and Gold 2008; Fuller et al. 2009; Hahn et al. 2010; Anticevic et al. 2011b; Leonard et al. 2017; Mayer et al. 2018). Working memory impairment has also been demonstrated in bipolar disorder (Adler et al. 2004; Glahn et al. 2006; Thompson et al. 2007; Mayer and Park 2012; Jensen et al. 2016). While working memory deficits appear to be particularly pronounced in manic or depressive phases (Townsend et al. 2010), they persist during euthymic phases of the illness (Xu et al. 2012), at least in a sizable number of patients (Volkert et al. 2015). Direct comparisons between patients with bipolar I (BPI) and bipolar II (BP-II) disorder indicate overall a similar degree of working memory impairment (Bora et al. 2011; Bora 2018). Additionally, there is evidence for a modestly greater degree of impairment in bipolar patients with a history of psychosis, compared to bipolar patients without a history of psychosis (Bora 2018).

One particularly relevant aspect of working memory is its limited capacity (Cowan 2001), which appears to constitute a core cognitive trait with high intra-individual stability over time (Kane and Engle 2002). Working memory capacity differs considerably between individuals and has strong links to high-level cognitive measures including global fluid intelligence, abstract reasoning, language abilities, mathematics, and overall scholastic performance (Daneman and Carpenter 1980; Cowan et al. 2005; Fukuda et al. 2010; Johnson, McMahon et al. 2013; Cowan 2014; Unsworth et al. 2014). Finding procognitive interventions which increase patients' working memory capacity should therefore also be a promising way to improve their general level of cognitive functioning (Johnson et al. 2013). Quantifying the degree to which working memory capacity is constrained across the schizo-bipolar spectrum is an important step toward this goal.

Based on the extensive body of work in the field of cognitive neuroscience (Luck and Vogel 2013), visual working memory capacity has been proposed as an especially suitable construct for this purpose (Barch et al. 2012). This is supported by its good construct validity and a number of specific properties. Visual working memory capacity correlates closely with measures of verbal working memory capacity but is less prone to chunking or rehearsal mechanisms (Luck and Vogel 1997; Cowan 2001), which could confound the estimation of pure working memory capacity. It has also been studied extensively using functional neuroimaging (Linden et al. 2003; Todd and Marois 2004; Vogel and Machizawa 2004). Conversely, spatial span paradigms are generally regarded as poorly suited for functional neuroimaging studies (Barch and Smith 2008). Additionally, paradigms assessing visual working memory capacity have good test-retest reliability (Xu et al. 2018; Dai et al. 2019) and have been employed successfully in animal studies (Wright et al. 2010).

Visual working memory capacity has been studied most commonly using change detection paradigms. Here, subjects have to remember one or more features such as color, location or orientation of an array of simple visual items. Subsequently, after a short delay interval they are shown a test array and have to make a judgment, whether the test array is identical or if a single item had changed. Healthy individuals are able to store information of about four objects at one time as integrated features (Luck and Vogel 1997; Wheeler and Treisman 2002). They are able to remember three to four items when required to encode a single feature such as color, or even two features of each item such as color and location. 
Variations of the 'canonical' change detection paradigm have also been implemented (Feuerstahler et al. 2019). In change localization paradigms, subjects need to specify which item has changed. In partial-report change detection paradigms, the change decision during the test array is limited to a single item. In multiple change detection paradigms, more than one item might change during the test array.

Reduced visual working memory capacity has been observed in schizophrenia (Gold et al. 2010; Mayer et al. 2012; Hahn et al. 2018) and in bipolar disorder I with a history of psychosis (Gold et al. 2018). However, to our knowledge, no study has compared visual working memory capacity in cohorts of patients with schizophrenia and schizoaffective disorder (PSZ) and patients with bipolar disorder (PBD) representing the full spectrum of both disorders. The main goal of our study was to assess working memory capacity in PBD of all illness subtypes, as well as PSZ using a canonical change detection paradigm. We expected to observe a gradient of reduced working memory capacity with greater impairment in PSZ than in PBD.

\section{Methods}

\section{Participants}

We recruited 62 PBD (42 female, mean age 42.05, range: 20-61), and 64 PSZ (26 female, mean age 38.56, range: $20-57, \mathrm{n}=41$ with schizophrenia and $\mathrm{n}=23$ with schizoaffective disorder) from psychiatric outpatient clinics in and around Frankfurt am Main, Germany. We established diagnoses of all patients according to DSM- 5 criteria based on a clinical interview and careful chart review at a consensus diagnosis meeting chaired by one of the authors (R.A.B.). We pooled both patients diagnosed with schizophrenia and schizoaffective disorder because long-term diagnostic stability and inter-rater reliability of schizoaffective disorder is relatively poor (Maj et al. 2000).

The Positive and Negative Syndrome Scale (PANSS) was used to assess current psychopathology in PSZ (Kay et al. 1987). In order to establish euthymic mood state in $\mathrm{PBD}$, participants were evaluated with the Young Mania Rating Scale (YMRS) and Montgomery-Åsberg Depression Rating Scale (MADRS) (Young et al. 1978; Montgomery and Åsberg 1979). Participants with YMRS values of $\geq 11$ or MADRS values of $\geq 11$ were excluded from our analysis.

70 matched healthy control subjects (HC), (44 female, mean age 38.61, range: 21-61) also participated. HC had no reported history of psychiatric illness, as well as no history in first-degree family members. They were recruited from the Frankfurt University campus and surrounding areas, as well as by online and printed advertisements. Current and past symptoms of psychiatric illness were ruled out using the German version of the Structural Clinical Interview SCID-I, from the Diagnostic and Statistical Manual, Version IV (Saß et al. 2003).

All participants reported no history of neurological illness and no drug use (excluding nicotine) within the past six months. All participants ranged in age from 20-61 years old. We matched subjects at the group level by conducting Kruskal-Wallis tests based on age $(H(2)=3.902, p=0.142)$, and participants' years of education $(H(2)=1.254, p=0.534)$, as well as parental years of education $(H(2)=0.834, p=0.659)$.

We assessed handedness as a continuous variable using the Edinburgh Handedness Inventory (Oldfield 1971). We compared handedness scores between groups using a Kruskal-Wallis test and did not find a significant difference $(H(2)=0.962, \mathrm{p}=0.618)$.

The German Mehrfachwahl-Wortschatz-Intelligenz Test (MWT-B) (Lehrl et al. 2005) was administered to assess premorbid verbal intelligence.

Further socio-demographic information for all cohorts can be found in Table 1. Prior to signing the informed consent form, participants were informed of its contents by the investigator and what to do in the case of experiencing distress, and how to end participation in the study. The ethics committee of the University Hospital Frankfurt approved all study procedures.

\section{Change detection task}

We implemented a 'canonical' color change detection task (Fig. 1) on a personal computer using Presentation software in Version14.9 (www.neurobs.com). Stimuli were presented on a grey background (RGB values: $191,191,191)$ in a dimly lit room with a viewing distance of approximately $60 \mathrm{~cm}$. Throughout the experiment, a black fixation cross was displayed at the center of the screen. Each trial began with the alert phase, during which the fixation cross turned to red for $500 \mathrm{~ms}$. This was followed by a preparation phase of $500 \mathrm{~ms}$. During the encoding phase a sample array of four colored circles was presented for $200 \mathrm{~ms}$. Each circle had a visual angle of approximately $0.95^{\circ}$. These circles were spaced equally apart on an imaginary circle with 12 possible locations around the black fixation cross covering a visual angle of approximately $5.25^{\circ}$, and the minimum distance between two circles was $0.29^{\circ}$. Each circle had one of seven easily discriminable possible colors with the following RGB values: black $(0,0,0)$, red $(255,0,0)$, white $(255,255$, $255)$, blue $(0,0,255)$, green $(0,255,0)$, yellow $(255$, $255,0)$, and magenta $(255,0,255)$, with no repetitions of colors within a trial. During the delay phase, the black fixation cross remained on the screen for 


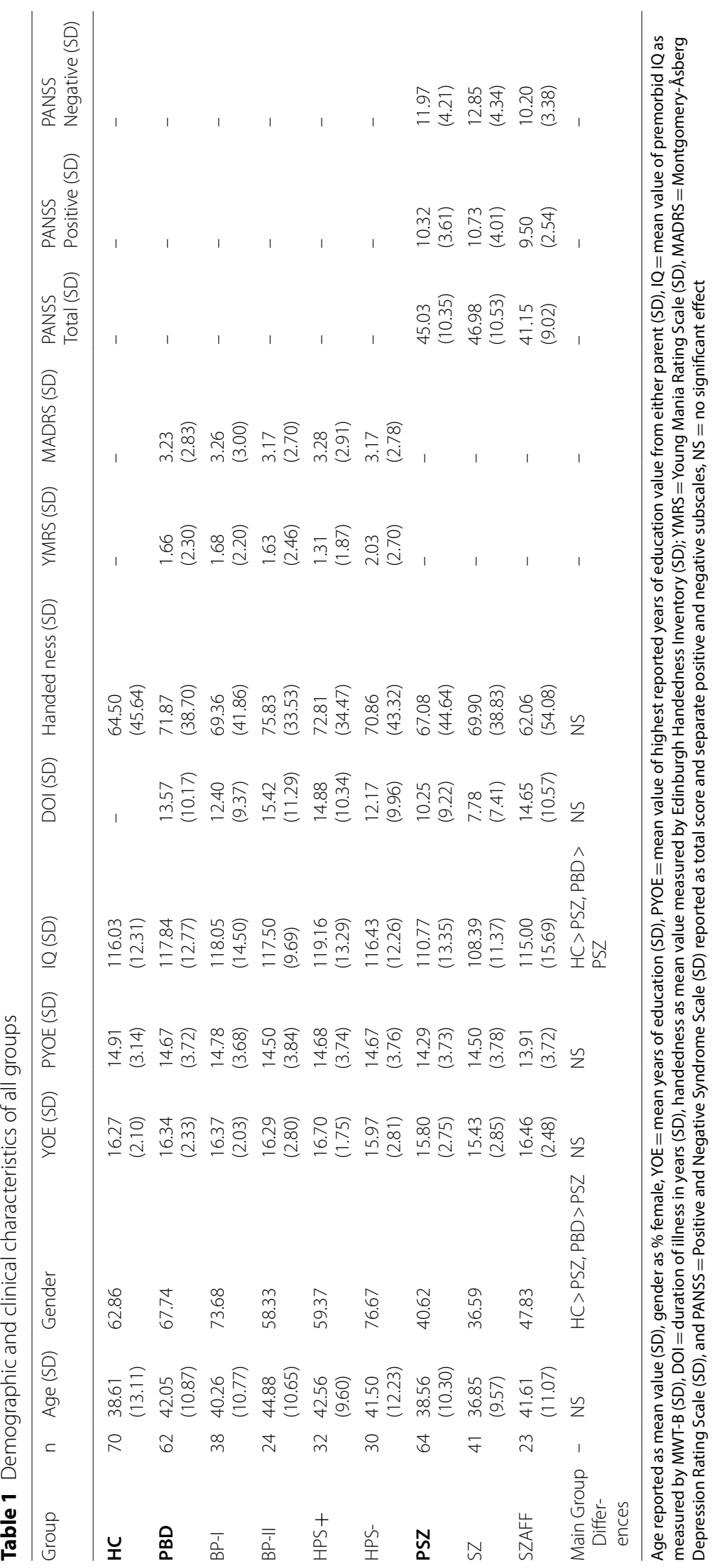




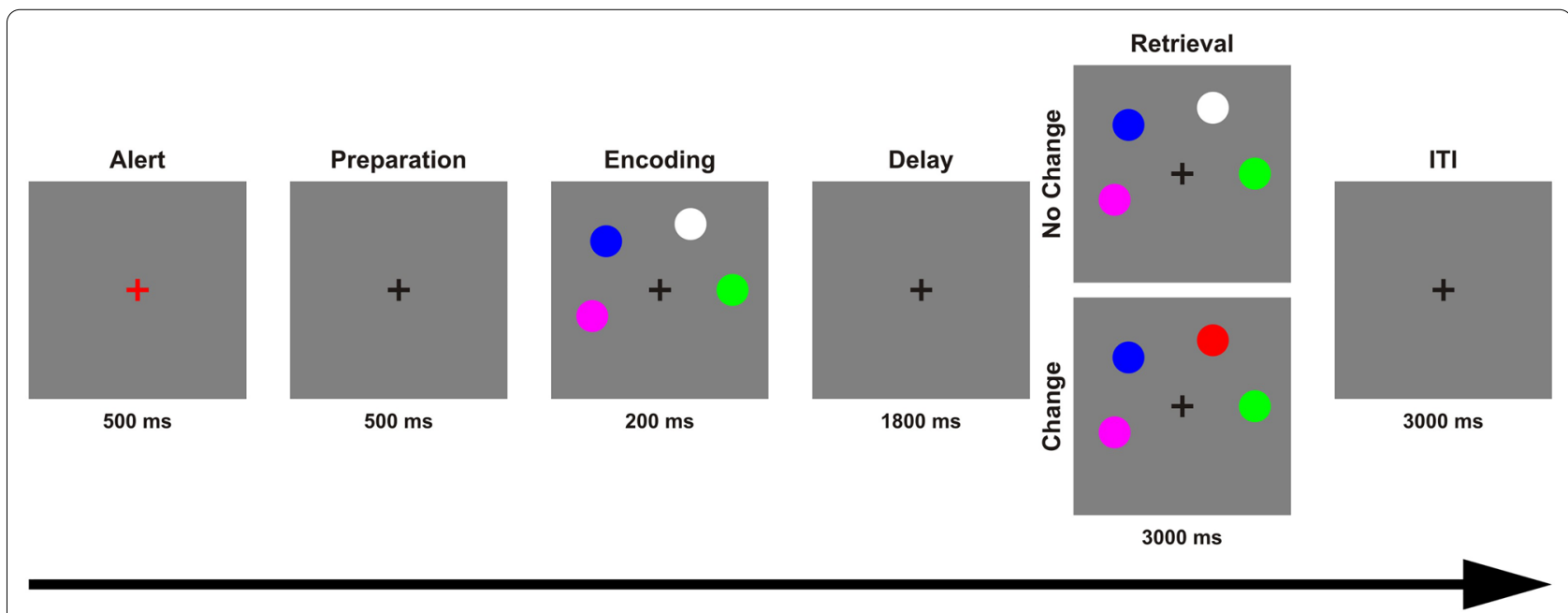

Fig. 1 The change detection task used to assess working memory capacity. Each trial began with the alert phase, during which the fixation cross turned to red for $500 \mathrm{~ms}$. This was followed by a preparation phase of $500 \mathrm{~ms}$. During the encoding phase a sample array of four colored circles was presented for $200 \mathrm{~ms}$. During the delay phase, the black fixation cross remained on the screen for $1800 \mathrm{~ms}$. The whole-display recognition test array followed, in which participants had a maximum duration of $3000 \mathrm{~ms}$ to decide if the test array was identical to the sample array presented in the encoding phase, or if one of the circles had changed color

1800 ms. A whole-display recognition test array followed, in which participants had a maximum duration of $3000 \mathrm{~ms}$ to decide if the test array was identical to the sample array presented in the encoding phase, or if one of the circles had changed color. Half of the trials were change trials (right mouse button), the other half no-change trials (left mouse button). In change trials, a randomly chosen circle changed its color. The total duration of each trial was $6000 \mathrm{~ms}$ followed by an inter-trial interval of $3000 \mathrm{~ms}$. All participants received the same instructions prior to the beginning the task, and were asked to perform as accurately as possible, and to keep their eyes fixated constantly on the center of the screen. A total of 60 trials were tested in each participant, which required approximately nine minutes of testing time.

\section{Medication scores}

Patients were on stable medication for at least one month at the time of study. One PSZ and two PBD did not receive medication. Details of medication can be found in Table 2. We calculated olanzapine equivalence scores for antipsychotic medication (Gardner et al. 2010), and daily doses for mood stabilizers (lithium, valproate and lamotrigine) in both patient groups.

\section{Calculation of working memory capacity}

In order to quantify the amount of information participants stored in working memory by each participant, we calculated Pashler's $K: K=\mathrm{N} \times((\mathrm{H}-\mathrm{FA}) /(1-\mathrm{FA})$ (Pashler 1988). $\mathrm{H}$ is the hit rate (proportion of correct responses to change trials). FA is the false alarm rate (proportion of incorrect responses to no-change trials).

Table 2 Medication of patients with bipolar disorder and patients with schizophrenia

\begin{tabular}{|c|c|c|c|c|c|c|c|c|c|c|c|}
\hline Group & FGA & SGA & FGA \& SGA & OES (SD) & Lithium & Lithium Dose (SD) & Valproate & $\begin{array}{l}\text { Valproate } \\
\text { Dose (SD) }\end{array}$ & Lamotrigine & $\begin{array}{l}\text { Lamotrigine } \\
\text { Dose (SD) }\end{array}$ & $\begin{array}{l}\text { Anti- } \\
\text { depressants }\end{array}$ \\
\hline $\mathrm{HC}$ & - & - & & - & - & - & - & - & - & - & - \\
\hline PBD & 0 & 35 & 0 & $\begin{array}{l}5.10 \\
(6.78), 35\end{array}$ & 29 & $\begin{array}{l}1078.62 \\
(401.68)\end{array}$ & 10 & $\begin{array}{l}1225.00 \\
(454.15)\end{array}$ & 10 & $\begin{array}{l}185.00 \\
(57.98)\end{array}$ & 23 \\
\hline PSZ & 1 & 62 & 5 & $\begin{array}{l}17.72 \\
(14.10) \\
62\end{array}$ & 3 & $\begin{array}{l}750.00 \\
(343.69)\end{array}$ & 2 & $\begin{array}{l}350.00 \\
(212.13)\end{array}$ & 0 & - & 14 \\
\hline
\end{tabular}

Number of patients receiving the different medication classes at time of study. FGA = first-generation antipsychotics, SGA $=$ second-generation antipsychotics. Olanzapine equivalence scores (OES) calculated according to Gardener et al. (2010), reported in mean (SD), and $n$ of patients. Lithium, valproate and lamotrigine doses reported as $\mathrm{n}$ of patients and mean daily $\mathrm{mg}$ value (SD). Antidepressants reported as $\mathrm{n}$ of patients receiving this type of medication 
$\mathrm{N}$ is the set size, which was always four. Our whole-display recognition paradigm required the use of Pashler's $K$ as the appropriate estimate of working memory capacity (Rouder et al. 2011).We excluded datasets with accuracy at or below chance level of (50\%) under the assumption that participants did not attend to the task, because they were thoroughly instructed and practiced the task with the experimenter. In total we excluded three PSZ; two had accuracies of $23 \%$, and one $40 \%$, one PBD with an accuracy of $23 \%$ and one $\mathrm{HC}$ with an accuracy of $47 \%$.

\section{Comparison of working memory capacity}

The goal of our primary analysis was to assess group differences of working memory capacity. A Shapiro-Wilk test across all three groups revealed that our working memory capacity estimates did not follow a normal distribution $(W(196)=0.88, p<0.01)$. Consequently, we used the non-parametric Kruskal-Wallis test for our primary planned analysis in order to detect working memory capacity differences across all three groups. We then conducted Mann-Whitney $U$ tests for pairwise comparisons and calculated the effect size with $r=z / \sqrt{ } \mathrm{N}$. We interpreted effect sizes as follows: large effect size $r=0.5$, medium $r=0.3$, and small $r=0.1$ (Cohen 1988).

\section{Investigation of possible demographic influences}

Nominally higher, but not significantly different premorbid IQ values were recorded in PBD (mean =117.84) than HC $($ mean $=116.03, r=0.07, p=0.307)$. Lower premorbid IQ was recorded in PSZ (mean $=110.77)$ compared to PBD $(r=0.26, p<0.001)$ and HC $(r=0.20, p=0.006)$. Gender was also not matched across participant groups $\left(\chi^{2}(2,196)=10.91, p=0.004\right)$. In order to control for the possible influences of group differences in premorbid IQ and gender on working memory capacity, we performed a one-way ANCOVA with the covariates premorbid IQ and gender. In order to test possible group differences in other demographic details including age, years of education, parental years of education, and handedness, we used Kruskal-Wallis tests.

\section{Investigation of possible influences of psychopathology}

We were also interested in the relationship between working memory capacity and clinical variables. To this end, we performed separate bivariate correlations in PBD and PSZ to examine the relationship between duration of illness, YMRS, MADRS, total PANSS scores, as well as the positive and negative subscales of PANSS with $K$.

\section{Investigation of possible medication effects}

There is evidence for an impact of antipsychotic medication (Reilly et al. 2006) and mood stabilizers (Khan et al.
2004; Senturk et al. 2007) on cognition, which might confound our analysis. We addressed this issue as follows.

We conducted a Mann-Whitney $U$ test in order to investigate possible group differences in olanzapine equivalence scores for both patient groups. We also conducted Spearman's $r$ bivariate correlations $\left(r_{s}\right)$ to examine the relationship between working memory capacity and olanzapine equivalence scores in both PSZ and PBD.

In addition, we conducted another Mann-Whitney $U$ test to check for a possible difference between $\mathrm{PBD}$ receiving antipsychotic medication at the time of the study and those PBD that were not receiving antipsychotic medication. We conducted additional Spearman's $r$ bivariate correlations to examine the relationship between working memory capacity and daily lithium dose only in PBD because only three patients in the PSZ group received lithium treatment. Similarly, we only conducted Spearman's r bivariate correlations between working memory capacity and daily valproate and lamotrigine doses in PBD because only two patients in the PSZ group received valproate and none received lamotrigine.

\section{Investigation of diagnostic subgroups}

In order to evaluate possible working memory capacity differences in patient subgroups, we reviewed the pairwise comparisons of Mann-Whitney $U$ tests of $K$ in patients with (a) schizophrenia (SZ) versus schizoaffective disorder (SZAFF), (b) BP-I versus BP-II, and (c) bipolar with a history of psychotic symptoms (BP HPS +) versus bipolar without a history of psychotic symptoms (BP HPS-).

\section{Results}

\section{Comparison of working memory capacity}

Working memory capacity was highest in $\mathrm{HC}$ (Mean $=3.39, \mathrm{SD}=0.61)$ followed by $\mathrm{PBD}($ Mean $=3.15$, $\mathrm{SD}=0.75)$ and then PSZ $($ Mean $=2.90, \mathrm{SD}=0.77)$. Our primary analysis revealed that $K$ was significantly different across all three groups $(H(2)=19.43, p<0.001)$. Pairwise group comparisons revealed a significant difference of $K$ between PSZ and HC with a medium effect size $(r=0.370, p<0.001)$ and between PBD and HC with a small effect size $(r=0.202, p=0.020)$. There was also a significant reduction of working memory capacity in PSZ compared to PBD with a small effect size $(r=0.201$, $p=0.024$ ) (Table 3).

\section{Investigation of possible demographic influences}

In a one-way ANCOVA there was no significant relation of premorbid IQ, the covariate, to $K$ across all groups $\left(F(1,191)=0.19\right.$, partial $\left.\mathrm{N}^{2}<0.01, p=0.661\right)$. There was also no significant relation of gender, the covariate to 
Table 3 Mean working memory (WM) capacity as estimated using Pashler's K(SD)

\begin{tabular}{|c|c|c|c|c|c|c|c|c|c|c|}
\hline & \multirow[t]{2}{*}{$\begin{array}{l}\text { WM Capacity } \\
\text { mean (SD) }\end{array}$} & \multicolumn{9}{|c|}{$\begin{array}{l}\text { Group comparisons } \\
\text { Effect size ( } p \text {-value) }\end{array}$} \\
\hline & & $\mathrm{HC}$ & PBD & BP-I & BP-II & BP HPS + & BP HPS- & PSZ & $S Z$ & SZAFF \\
\hline $\mathrm{HC}$ & $\begin{array}{l}3.39 \\
(0.61)\end{array}$ & - & $\begin{array}{l}0.202 \\
(0.020)^{*}\end{array}$ & $\begin{array}{l}0.167 \\
(0.082)\end{array}$ & $\begin{array}{l}0.214 \\
(0.038)^{*}\end{array}$ & $\begin{array}{l}0.216 \\
(0.029)^{*}\end{array}$ & $\begin{array}{l}0.156 \\
(0.120)\end{array}$ & $\begin{array}{l}0.370 \\
(<0.001)^{*}\end{array}$ & $\begin{array}{l}0.340 \\
(<0.001)^{*}\end{array}$ & $\begin{array}{l}0.347 \\
(<0.001)^{*}\end{array}$ \\
\hline PBD & $\begin{array}{l}3.15 \\
(0.75)\end{array}$ & $\begin{array}{l}0.202 \\
(0.020)^{*}\end{array}$ & - & - & - & - & - & $\begin{array}{l}0.201 \\
(0.024)^{*}\end{array}$ & - & - \\
\hline BP-I & $\begin{array}{l}3.22 \\
(0.62)\end{array}$ & $\begin{array}{l}0.167 \\
(0.082)\end{array}$ & - & - & $\begin{array}{l}0.104 \\
(0.414)\end{array}$ & - & - & - & $\begin{array}{l}0.211 \\
(0.061)\end{array}$ & $\begin{array}{l}0.290 \\
(0.025)^{*}\end{array}$ \\
\hline BP-II & $\begin{array}{l}3.03 \\
(0.92)\end{array}$ & $\begin{array}{l}0.214 \\
(0.038)^{*}\end{array}$ & - & $\begin{array}{l}0.104 \\
(0.414)\end{array}$ & - & - & - & - & $\begin{array}{l}0.105 \\
(0.395)\end{array}$ & $\begin{array}{l}0.180 \\
(0.217)\end{array}$ \\
\hline BP HPS + & $\begin{array}{l}3.19 \\
(0.56)\end{array}$ & $\begin{array}{l}0.216 \\
(0.029)^{*}\end{array}$ & - & - & - & - & $\begin{array}{l}0.038 \\
(0.767)\end{array}$ & - & $\begin{array}{l}0.169 \\
(0.148)\end{array}$ & $\begin{array}{l}0.262 \\
(0.052)\end{array}$ \\
\hline BP HPS- & $\begin{array}{l}3.10 \\
(0.92)\end{array}$ & $\begin{array}{l}0.156 \\
(0.120)\end{array}$ & - & - & - & $\begin{array}{l}0.038 \\
(0.767)\end{array}$ & & - & $\begin{array}{l}0.171 \\
(0.150)\end{array}$ & $\begin{array}{l}0.233 \\
(0.090)\end{array}$ \\
\hline PSZ & $\begin{array}{l}2.90 \\
(0.77)\end{array}$ & $\begin{array}{l}0.370 \\
(<0.001)^{*}\end{array}$ & $\begin{array}{l}0.201 \\
(0.024)^{*}\end{array}$ & - & - & - & - & - & - & - \\
\hline SZ & $\begin{array}{l}2.89 \\
(0.81)\end{array}$ & $\begin{array}{l}0.340 \\
(<0.001)^{*}\end{array}$ & - & $\begin{array}{l}0.211 \\
(0.061)\end{array}$ & $\begin{array}{l}0.105 \\
(0.395)\end{array}$ & $\begin{array}{l}0.169 \\
(0.148)\end{array}$ & $\begin{array}{l}0.171 \\
(0.150)\end{array}$ & - & - & $\begin{array}{l}-0.047 \\
(0.705)\end{array}$ \\
\hline SZAFF & $\begin{array}{l}2.90 \\
(0.70)\end{array}$ & $\begin{array}{l}0.347 \\
(<0.001)^{*}\end{array}$ & - & $\begin{array}{l}0.290 \\
(0.025)^{*}\end{array}$ & $\begin{array}{l}0.180 \\
(0.217)\end{array}$ & $\begin{array}{l}0.262 \\
(0.052)\end{array}$ & $\begin{array}{l}0.233 \\
(0.090)\end{array}$ & - & $\begin{array}{l}-0.047 \\
(0.705)\end{array}$ & - \\
\hline
\end{tabular}

Results of Mann-Whitney $\mathrm{U}$ tests to test pairwise comparisons of working memory capacity estimated with Pashler's $\mathrm{K}$ and reported as effect size $(r=z / \sqrt{ } \mathrm{N})$ and $p$-value. $\mathrm{HC}=$ healthy controls, $\mathrm{PBD}=$ patients with bipolar disorder, BP-I= patients with bipolar type I, BP-II= bipolar patients with bipolar type II, BP HPS $+=$ bipolar patients with history of psychotic symptoms, BP HPS- = bipolar patients without history of psychotic symptoms, PSZ = patients with schizophrenia, $\mathrm{SZ}=$ patients with schizophrenia, SZAFF = patients with schizoaffective disorder. Statistical significance is indicated by *

$K$ across all groups $\left(F(1,191)=1.56\right.$, partial $\mathrm{N}^{2}<0.01$, $p=0.213)$. A significant effect of group on $K$ was still observed after controlling for both the effects of premorbid IQ and gender $\left(F(2,191)=6.90\right.$, partial $\mathrm{N}^{2}=0.07$, $p=0.001)$.

\section{Investigation of possible psychopathological influences}

There was no significant correlation between $K$ and years of illness in either PBD $\left(r_{s}=-0.15, p=0.254, n=62\right)$, or PSZ $\left(r_{s}<-0.01, p=0.961, n=64\right)$. There was no significant correlation between $K$ and scores on the YMRS $\left(r_{s}=0.10, p=0.449\right)$, or MADRS $\left(r_{s}=-0.15, p=0.239\right)$ in PBD. There was no significant correlation between $K$ and total PANSS scores $\left(r_{s}=-0.15, p=0.242\right)$, as well as PANSS positive $\left(r_{s}=-0.22, p=0.093\right)$, and PANSS negative subscale $\left(r_{s}<0.01, p=0.947\right)$ in PSZ.

\section{Investigation of possible medication effects}

We recorded higher olanzapine equivalence scores in PSZ $(M d n=13.41)$ compared to PBD $(M d n=2.50)$ $(U=626.50, \quad z=-6.60, \quad r=0.67, p<0.001)$. Yet, we observed no significant correlation of $K$ with olanzapine equivalence scores in either PSZ $\left(r_{s}=-0.16, p=0.202\right.$, $n=62)$, or PBD $\left(r_{s}=-0.14, p=0.285, n=35\right)$. No significant difference was detected between $K$ in PBD taking antipsychotic medication $(M d n=3.31)$ and those not taking antipsychotic medication $(M d n=3.41)$ ( $U=427.00, z=-0.646, r=0.08, p=0.518)$. Similarly, we observed no significant correlation between $K$ and daily lithium dose in $\operatorname{PBD}\left(r_{s}=-0.07, p=0.721, n=29\right)$, as well as $K$ and daily valproate dose $\left(r_{s}=-0.39, p=0.263\right.$, $n=10)$, and $K$ and daily lamotrigine dose $\left(r_{s}=-0.51\right.$, $p=0.136, n=10)$ in PBD.

\section{Investigation of diagnostic subgroups}

Regarding our exploratory patient subgroup analyses, we observed no significant differences of $K$ in any of the following Mann-Whitney U tests. This included the comparison of (a) schizophrenia (SZ) versus schizoaffective disorder (SZAFF) $(r=0.047, p=0.705)$, (b) bipolar I (BPI) versus bipolar II (BP-II) $(r=0.104, p=0.414)$, and (c) bipolar with a history of psychotic symptoms (BP HPS + ) versus bipolar without a history of psychotic symptoms (BP HPS-) $(r=0.038, p=0.767)$ (Table 3). We consider these analyses exploratory as the sample sizes were relatively small, groups were not matched well and the effect sizes were all small.

\section{Discussion}

We investigated working memory capacity in bipolar disorder and schizophrenia compared to healthy controls in order to elucidate the degree of working memory 
impairment in these major psychiatric disorders. We observed a significant reduction in working memory capacity in PBD compared to HC and in PSZ compared to HC. Working memory capacity of PBD fell between PSZ and HC with a significant difference between both patient groups.

Our results indicate a gradient of reduced working memory capacity across the schizo-bipolar spectrum, with PSZ showing a stronger impairment with a medium effect size. By comparison, working memory capacity reduction in PBD was less pronounced with a small effect size. These findings match previous studies on working memory dysfunction in both disorders, which indicate a similar intermediate level of working memory impairment in PBD (Hamilton et al. 2009; Barch and Sheffield 2014). Our findings are also well in line with previous studies demonstrating a comparable gradient of impairment across a wide range of other cognitive domains (Goldberg 1999; Schretlen et al. 2007; Ivleva et al. 2010; Lewandowski et al. 2011; Hill et al. 2013; Reilly and Sweeney 2014).

Our three participant groups differed in their levels of premorbid IQ. We report significantly higher premorbid IQ in PBD and HC as compared to in PSZ, and no significant difference between PBD and HC. However, there is evidence, that premorbid intelligence scores tend to be lower in PSZ (Crawford et al. 1992; Khandaker et al. 2011), and supranormal in multiple measurements in PBD (Bora 2015). Nevertheless, we did not observe a significant influence of premorbid IQ on $K$, which is unsurprising considering we measured crystallized intelligence. In comparison, fluid intelligence seems to be correlated with working memory capacity (Fukuda et al. 2010).

Recently, a large multi-center study using both a change localization and a multiple change detection task reported an overall reduction of visual working memory capacity across psychotic disorders, i.e. schizophrenia, schizoaffective disorder and BP-I with a history of psychosis (Gold et al. 2018). The authors did not observe a significant difference between any of the three patient groups in either task. For the change localization task, visual working memory capacity was significantly lower in all three patient groups. Interestingly, for the multiple change detection task this reduction was most pronounced in patients with bipolar I disorder with a lifetime history of psychosis, with only a trend towards a significant reduction in patients with schizophrenia. These results indicate that visual working memory capacity reduction in BP-I with a lifetime history of psychosis is similar in magnitude to schizophrenia. However, it remains unclear, whether this similarity is attributable to the shared presence of psychosis, because the study did not include either BP-I without a lifetime history of psychosis or BP-II. In contrast to Gold et al., we observed an intermediate level of visual working memory capacity reduction in PBD. Several factors could account for this discrepancy. Firstly, we studied the full bipolar spectrum including BP-I without a history of psychosis and BP-II, rather than focusing only on the effect of psychotic illness across diagnostic categories. Interestingly, our exploratory subgroup analyses did not indicate a difference in visual working memory capacity between BP-I and BP-II. We also did not observe an effect of lifetime history of psychosis within the PBD group. However, these posthoc findings need to be interpreted with caution due to the relatively small size of our subgroups.

There were also important differences in the paradigms employed. The number of possible changes might have influenced our results. Gold et al. observed a significant difference between healthy controls and all patient groups for their change localization task, which was a single change paradigm. By contrast, group differences were less pronounced in their multiple change detection paradigm with either zero, one, two, or five changes. Furthermore, we consistently maintained a set size of four objects, while Gold et al. used a set size of five objects. This difference might have affected results, because performance continues to decline as set size increases (Luck and Vogel 1997). This interpretation would also be in line with the notion, that deficits in PBD become more pronounced in tasks greatly exceeding their working memory capacity. It has been suggested, that a larger set size might have influenced subjects' strategies and minimized between-group differences (Gold et al. 2018). Conversely, there was some indication of a ceiling effect in the $\mathrm{HC}$ group in our data with $13 \mathrm{HC}$ having a $K$ of 4.0 compared to three PBD and two PSZ (Fig. 2). This implies, that our set size might have underestimated working memory capacity differences between HC and both PBD and PSZ. Using both set sizes within the same study might help to clarify this issue.

Our observation of a transdiagnostic reduction of working memory capacity across the schizo-bipolar spectrum raises the question, which cognitive mechanisms might be responsible. It has been proposed that the limits of working memory capacity are determined primarily by the amount of information which can be held in the focus of attention (Cowan 2001). Specifically, top-down attention appears to be crucial for the selection of information to be stored in working memory. The efficiency of this "gatekeeper" function has a substantial impact on working memory capacity (Vogel et al. 2005; Cowan and Morey 2006; McNab and Klingberg 2008). Thus, impaired attentional processes in patients might have contributed to our results. To our best knowledge, the potential impact of attentional dysfunction on working memory 


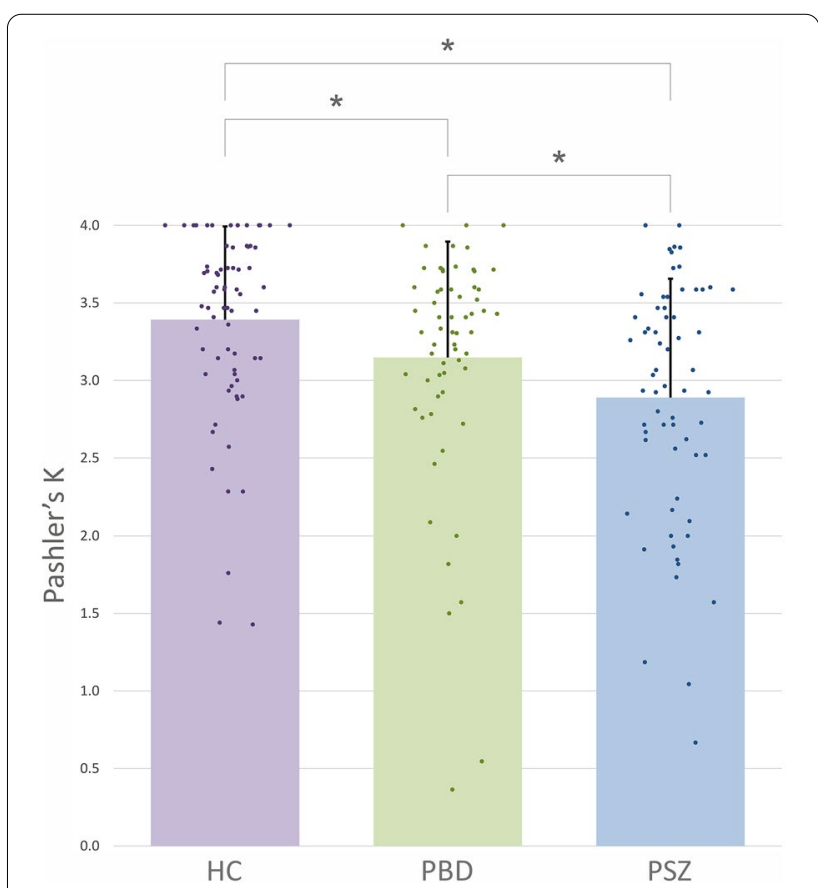

Fig. 2 Working memory capacity for all groups. Working memory capacity was estimated using Pashler's K. Bars indicate mean group average and scatter plot data indicates individual capacity estimates for healthy controls $(\mathrm{HC})$ in purple, patients with bipolar disorder (PBD) in green, and patients with schizophrenia (PSZ) in blue. Error bars indicate standard deviation

impairment in bipolar disorder remains unknown. However, for schizophrenia there is experimental support for the presence of a selective impairment of top-down attentional control, which may disturb working memory encoding (Mayer et al. 2012). Furthermore, there is considerable evidence for a tendency in PSZ to show hyperfocusing of attention when processing visual information (Luck et al. 2019b). In the context of visual working memory, hyperfocusing might limit the amount of items which PSZ can focus on, thereby restricting the amount of information they can successfully encode (Leonard et al. 2013; Luck et al. 2019a).

This interpretation would also be compatible with a component-process model of working memory dysfunction in PSZ, which is based on converging behavioral and neuroimaging evidence for a primary impairment of working memory during the encoding stage (Tek et al. 2002; Hartman et al. 2003; Lee and Park 2005; Kim et al. 2006; Javitt et al. 2007; Fuller et al. 2009; Gold et al. 2010; Hahn et al. 2010; Anticevic et al. 2011a; Mayer et al. 2012).

Deficits during working memory encoding have been linked to impaired early-stage visual processing (Haenschel et al. 2007, 2009) as well as to disturbed interactions between prefrontal areas and visual areas closely involved in object processing (Bittner et al. 2015). So far it remains unclear, to which degree disturbances during the initial encoding of information contribute specifically to reduced working memory capacity in bipolar disorder and schizophrenia. Interestingly, there is evidence for differential mechanisms underlying working memory impairment in schizophrenia and bipolar disorder. While both groups were impaired in a spatial delayed response task, only patients with schizophrenia recorded more false memory responses by confidently responding that the information was correctly encoded even though it was not (Mayer and Park 2012).

Furthermore, there is evidence for an additional impairment of working memory maintenance in schizophrenia (Reilly et al. 2006; Stephane and Pellizzer 2007; Badcock et al. 2008), which could also contribute to reduced working memory capacity. Conversely, so far the presence of working memory maintenance deficits has not been investigated in patients with bipolar disorder. Future studies should try to elucidate the contribution of specific component processes to reduced working memory capacity across both disorders.

Importantly, two different models for working memory storage have been discussed. Originally, a discrete-slots model was proposed, where a specific number of items are stored up to capacity, and nothing is stored from the remaining items (Miller 1956; Luck and Vogel 1997; Cowan 2001). More recently, working memory capacity has been studied using a limited-resource model in which a dynamic precision resource spreads out across objects, such that a smaller amount of objects are encoded with higher precision (Bays and Husain 2008; Peters et al. 2018). While our paradigm was able to measure working memory capacity in a slot model, both the discreteslot model and limited-resource model should be studied within the same patient groups.

It remains to be seen, whether the gradient of working memory capacity reduction is attributable to a comparable gradual manifestation of the same neurophysiological disturbances across diagnostic categories. Our findings also need to be reconciled with the disconnection hypothesis (Friston and Frith 1995), a parsimonious and well validated model for core cognitive and clinical features of schizophrenia that has also been recently applied to bipolar disorder (Perry et al. 2019). Functional neuroimaging studies are required to illuminate these issues.

\section{Conclusion}

To summarize, our data provide evidence for reduced visual working memory capacity in both bipolar disorder and schizophrenia. The observed gradient of cognitive dysfunction is compatible with the 
neurodevelopmental continuum model (Owen and O'Donovan 2017), which would place bipolar disorder between schizophrenia and healthy controls on a neurodevelopmental gradient, matching the degree and persistence of overall functional impairment in both disorders. This interpretation should be validated by investigating the transdiagnostic impact of genetic risk variants - especially CNVs - in genetic pathways regulating neurodevelopment on working memory capacity. However, there is also evidence for a contribution of additional pathophysiological factors such as inflammation (Bora 2019; Millett et al. 2019) to cognitive impairment in both disorders. Future studies should try to determine the specific contributions of such factors to reduced visual working memory capacity. Similarly, it remains an open question how shared and distinct genetic and environmental risk factors for either disorder might influence working memory capacity on the cognitive and neurophysiological level. Given their relevance for patients' functional capacity, future studies should also examine whether pro-cognitive interventions such as cognitive remediation could improve these deficits across diagnostic categories. Finally, our results highlight the utility of established constructs based on cognitive neuroscience for the investigation of impaired information processing in bipolar disorder similar to such endeavors in schizophrenia research (Barch and Smith 2008).

\section{Abbreviations \\ PBD: Patients with bipolar disorder; PSZ: Patients with schizophrenia; HC: Healthy controls; YMRS: Young Mania Rating Scale; MADRS: Montgomery- Åsberg Depression Rating Scale; PANSS: The Positive and Negative Syndrome Scale; BP-I: Patients with bipolar I; BP-II: Patients with bipolar II; SZ: Patients with schizophrenia; SZAFF: Patients with schizoaffective disorder; BP HPS + : Bipolar with a history of psychotic symptoms; BP HPS-: Bipolar without a history of psychotic symptoms; K: Pashler's K; SCID-I: Structural Clinical Interview; SD: Standard deviation; YOE: Years of education; PYOE: Parental years of education; DOI: Duration of illness; MWT-B: German Mehrfachwahl-Wortschatz-Intelligenz Test.}

\section{Acknowledgements}

The authors are grateful to Benjamin Peters and Meike Hettwer for helpful discussions, to Peter Hustedt, Michael Grube, Christoph Fehr, Martin Hambrecht for their support in recruiting patients, as well as to Lisa Goldschmidt, Tobias Lehmann, and Deliah Macht for help with data acquisition.

\section{Authors' contributions \\ All authors made substantial contributions to the conception or design of the work, or the acquisition, analysis or interpretation of data. Authors RAB and LR designed the experiment. Authors CVB-S, CP and LR acquired the data. Authors CVB-S, CP, JSM, SM and RAB analyzed the data. Authors CVB-S and RAB undertook the literature searches and wrote the first draft of the manuscript. All authors contributed to and revised the manuscript. All authors read and approved the final manuscript.}

\section{Funding}

Open Access funding enabled and organized by Projekt DEAL. C.V BarnesScheufler was supported by a "main doctus" scholarship from The Polytechnic Foundation of Frankfurt am Main.

\section{Availability of data and materials}

The datasets used during the current study are available from the corresponding author on reasonable request.

\section{Declarations}

Ethics approval and consent to participate

The ethics committee of the University Hospital Frankfurt approved all study procedures. The study was carried out following the rules of the Declaration of Helsinki.

\section{Consent for publication}

Not applicable.

\section{Competing interests}

The authors declare that they have no competing interests.

\section{Author details}

${ }^{1}$ Department of Psychiatry, Psychosomatic Medicine, and Psychotherapy, University Hospital Frankfurt, Goethe University, Heinrich-Hoffmann-Str. 10, 60528 Frankfurt am Main, Germany. ${ }^{2}$ Netherlands Institute for Neuroscience, Amsterdam, The Netherlands. ${ }^{3}$ Department of Child and Adolescent Psychiatry, Psychosomatics and Psychotherapy, University Hospital Frankfurt, Goethe University, Frankfurt am Main, Germany. ${ }^{4}$ Department of Psychiatry, Psychosomatic Medicine, and Psychotherapy, University Hospital Würzburg, Würzburg, Germany. ${ }^{5}$ Ernst Strüngmann Institute for Neuroscience (ESI) in Cooperation with Max Planck Society, Frankfurt am Main, Germany.

Received: 5 March 2020 Accepted: 22 December 2020 Published online: 02 April 2021

\section{References}

Adler CM, Holland SK, Schmithorst V, Tuchfarber MJ, Strakowski SM. Changes in neuronal activation in patients with bipolar disorder during performance of a working memory task. Bipolar Disord. 2004;6(6):540-9.

Anticevic A, Repovs G, Barch DM. Working memory encoding and maintenance deficits in schizophrenia: neural evidence for activation and deactivation abnormalities. Schizophr Bull. 2011a;39(1):168-78.

Anticevic A, Repovs G, Corlett PR, Barch DM. Negative and nonemotional interference with visual working memory in schizophrenia. Biol Psychiatry. 2011b;70(12):1159-68.

Anttila V, Bulik-Sullivan B, Finucane HK, Walters RK, Bras J, Duncan L, EscottPrice V, Falcone GJ, Gormley P, Malik R. Analysis of shared heritability in common disorders of the brain. Science. 2018;360(6395):8757.

Badcock JC, Badcock DR, Read C, Jablensky A. Examining encoding imprecision in spatial working memory in schizophrenia. Schizophr Res. 2008;100(1-3):144-52.

Baddeley A. Working memory. Science. 1992;255(5044):556-9.

Baddeley AD, Hitch G. Working memory. Psychol Learning Motivat. 1974;8:47-89.

Barch DM, Moore H, Nee DE, Manoach DS, Luck SJ. CNTRICS imaging biomarkers selection: Working memory. Schizophr Bull. 2012;38(1):43-52.

Barch DM, Sheffield JM. Cognitive impairments in psychotic disorders: common mechanisms and measurement. World Psychiatry. 2014;13(3):224-32.

Barch DM, Smith E. The cognitive neuroscience of working memory: relevance to CNTRICS and schizophrenia. Biol Psychiatry. 2008;64(1):11-7.

Bays PM, Husain M. Dynamic shifts of limited working memory resources in human vision. Science. 2008;321(5890):851-4.

Bittner RA, Linden DE, Roebroeck A, Hartling F, Rotarska-Jagiela A, Maurer K, Goebel R, Singer W, Haenschel C. The when and where of working memory dysfunction in early-onset schizophrenia-a functional magnetic resonance imaging study. Cereb Cortex. 2015;25(9):2494-506.

Bora E. Developmental trajectory of cognitive impairment in bipolar disorder: comparison with schizophrenia. Eur Neuropsychopharmacol. 2015:25(2):158-68.

Bora E. Neurocognitive features in clinical subgroups of bipolar disorder: a meta-analysis. J Affect Disord. 2018;229:125-34. 
Bora E. Peripheral inflammatory and neurotrophic biomarkers of cognitive impairment in schizophrenia: A meta-analysis. Psychol Med. 2019:49(12):1971-9

Bora E, Pantelis C. Meta-analysis of cognitive impairment in first-episode bipolar disorder: comparison with first-episode schizophrenia and healthy controls. Schizophr Bull. 2015;41(5):1095-104.

Bora E, Yücel M, Pantelis C, Berk M. Meta-analytic review of neurocognition in bipolar II disorder. Acta Psychiatr Scand. 2011;123(3):165-74.

Bortolato B, Miskowiak KW, Köhler CA, Vieta E, Carvalho AF. Cognitive dysfunction in bipolar disorder and schizophrenia: a systematic review of metaanalyses. Neuropsychiatr Dis Treat. 2015;11:3111.

Clementz BA, Sweeney JA, Hamm JP, Ivleva El, Ethridge LE, Pearlson GD, Keshavan MS, Tamminga CA. Identification of distinct psychosis biotypes using brain-based biomarkers. Am J Psychiatry. 2016;173(4):373-84.

Cohen J. Statistical power analysis. 1988.

Cowan N. The magical number 4 in short-term memory: a reconsideration of mental storage capacity. Behav Brain Sci. 2001;24(1):87-114.

Cowan N. Working memory underpins cognitive development, learning, and education. Educ Psychol Rev. 2014;26(2):197-223.

Cowan N, Elliott EM, Saults JS, Morey CC, Mattox S, Hismjatullina A, Conway AR. On the capacity of attention: Its estimation and its role in working memory and cognitive aptitudes. Cogn Psychol. 2005;51(1):42-100.

Cowan N, Morey CC. Visual working memory depends on attentional filtering Trends Cogn Sci. 2006:10(4):139-41.

Crawford JR, Besson J, Bremner M, Ebmeier K, Cochrane R, Kirkwood K. Estimation of premorbid intelligence in schizophrenia. Br J Psychiatry. 1992:161(1):69-74.

Cuthbert BN. The RDoC framework: facilitating transition from ICD/DSM to dimensional approaches that integrate neuroscience and psychopathology. World Psychiatry. 2014;13(1):28-35.

Dai M, Li Y, Gan S, Du F. The reliability of estimating visual working memory capacity. Scientific reports. 2019;9(1):1-8.

Daneman M, Carpenter PA. Individual differences in working memory and reading. J Mem Lang. 1980;19(4):450.

Feuerstahler LM, Luck SJ, MacDonald A, Waller NG. A note on the identification of change detection task models to measure storage capacity and attention in visual working memory. Behav Res Methods. 2019;51(3):1360-70

Friston KJ, Frith CD. Schizophrenia: a disconnection syndrome. Clin Neurosci. 1995;3(2):89-97.

Fukuda K, Vogel E, Mayr U, Awh E. Quantity, not quality: The relationship between fluid intelligence and working memory capacity. Psychon Bull Rev. 2010;17(5):673-9.

Fuller RL, Luck SJ, Braun EL, Robinson BM, McMahon RP, Gold JM. Impaired visual working memory consolidation in schizophrenia. Neuropsychology. 2009;23(1):71-80.

Gardner DM, Murphy AL, O'Donnell H, Centorrino F, Baldessarini RJ. International consensus study of antipsychotic dosing. Am J Psychiatry. 2010;167(6):686-93.

Glahn DC, Bearden CE, Cakir S, Barrett JA, Najt P, Serap Monkul E, Maples N, Velligan DI, Soares JC. Differential working memory impairment in bipolar disorder and schizophrenia: effects of lifetime history of psychosis. Bipolar Disord. 2006:8(2):117-23.

Gold JM, Barch DM, Feuerstahler LM, Carter CS, MacDonald AW 3rd, Ragland JD, Silverstein SM, Strauss ME, Luck SJ. Working Memory Impairment Across Psychotic disorders. Schizophr Bull. 2018;12:33.

Gold JM, Hahn B, Zhang WW, Robinson BM, Kappenman ES, Beck VM, Luck SJ. Reduced capacity but spared precision and maintenance of working memory representations in schizophrenia. Arch Gen Psychiatry. 2010;67(6):570-7.

Goldberg TE. Some fairly obvious distinctions between schizophrenia and bipolar disorder. Schizophr Res. 1999;39(2):127-32.

Haenschel C, Bittner RA, Haertling F, Rotarska-Jagiela A, Maurer K, Singer W, Linden DE. Contribution of impaired early-stage visual processing to working memory dysfunction in adolescents with schizophrenia: a study with event-related potentials and functional magnetic resonance imaging. Arch Gen Psychiatry. 2007;64(11):1229-40.

Haenschel C, Bittner RA, Waltz J, Haertling F, Wibral M, Singer W, Linden DE, Rodriguez E. Cortical oscillatory activity is critical for working memory as revealed by deficits in early-onset schizophrenia. J Neurosci. 2009:29(30):9481-9.
Hahn B, Robinson BM, Kaiser ST, Harvey AN, Beck VM, Leonard CJ, Kappenman ES, Luck SJ, Gold JM. Failure of schizophrenia patients to overcome salient distractors during working memory encoding. Biol Psychiatry. 2010;68(7):603-9.

Hahn B, Robinson BM, Leonard CJ, Luck SJ, Gold JM. Posterior parietal cortex dysfunction is central to working memory storage and broad cognitive deficits in schizophrenia. J Neurosci. 2018;34:8.

Hamilton LS, Altshuler LL, Townsend J, Bookheimer SY, Phillips OR, Fischer J, Woods RP, Mazziotta JC, Toga AW, Nuechterlein KH. Alterations in functional activation in euthymic bipolar disorder and schizophrenia during a working memory task. Hum Brain Mapp. 2009;30(12):3958-69.

Hartman M, Steketee MC, Silva S, Lanning K, McCann H. Working memory and schizophrenia: evidence for slowed encoding. Schizophr Res. 2003:59(2-3):99-113.

Hill SK, Reilly JL, Keefe RS, Gold JM, Bishop JR, Gershon ES, Tamminga CA, Pearlson GD, Keshavan MS, Sweeney JA. Neuropsychological impairments in schizophrenia and psychotic bipolar disorder: findings from the BipolarSchizophrenia Network on Intermediate Phenotypes (B-SNIP) study. Am J Psychiatry. 2013;170(11):1275-84

Insel T, Cuthbert B, Garvey M, Heinssen R, Pine DS, Quinn K, Sanislow C, Wang P. Research domain criteria (RDoC): toward a new classification framework for research on mental disorders. Am Psychiatric Assoc. 2010;87:4567.

Insel TR. The NIMH research domain criteria (RDoC) project: precision medicine for psychiatry. Am J Psychiatry. 2014;171(4):395-7.

Ivleva El, Morris DW, Moates AF, Suppes T, Thaker GK, Tamminga CA. Genetics and intermediate phenotypes of the schizophrenia-bipolar disorder boundary. Neurosci Biobehav Rev. 2010;34(6):897-921.

Javitt DC, Rabinowicz E, Silipo G, Dias EC. Encoding vs. retention: differential effects of cue manipulation on working memory performance in schizophrenia. Schizophr Res. 2007:91(1-3):159-68.

Jensen JH, Knorr U, Vinberg M, Kessing LV, Miskowiak KW. Discrete neurocognitive subgroups in fully or partially remitted bipolar disorder: associations with functional abilities. J Affect Disord. 2016;205:378-86.

Johnson MK, McMahon RP, Robinson BM, Harvey AN, Hahn B, Leonard CJ, Luck SJ, Gold JM. The relationship between working memory capacity and broad measures of cognitive ability in healthy adults and people with schizophrenia. Neuropsychology. 2013;27(2):220-9.

Kahn RS, Keefe RS. Schizophrenia is a cognitive illness: time for a change in focus. JAMA psychiatry. 2013;70(10):1107-12.

Kane MJ, Engle RW. The role of prefrontal cortex in working-memory capacity, executive attention, and general fluid intelligence: An individual-differences perspective. Psychon Bull Rev. 2002;9(4):637-71.

Kay SR, Fiszbein A, Opler LA. The positive and negative syndrome scale (PANSS) for schizophrenia. Schizophr Bull. 1987;13(2):261-76.

Khan A, Ginsberg LD, Asnis GM, Goodwin FK, Davis KH, Krishnan AA, Adams BE. Effect of lamotrigine on cognitive complaints in patients with bipolar I disorder. J Clin Psychiatry. 2004;65(11):1483-90.

Khandaker GM, Barnett JH, White IR, Jones PB. A quantitative meta-analysis of population-based studies of premorbid intelligence and schizophrenia. Schizophr Res. 2011;132(2-3):220-7.

Kim J, Park S, Shin Y-W, Lee KJ, Kwon JS. Self-initiated encoding facilitates object working memory in schizophrenia: implications for the etiology of working memory deficit. Schizophr Res. 2006;82(1):65-74.

Lee J, Park S. Working memory impairments in schizophrenia: a meta-analysis. J Abnorm Psychol. 2005;114(4):599.

Lee PH, Anttila V, Won H, Feng Y-CA, Rosenthal J, Zhu Z, Tucker-Drob EM, Nivard MG, Grotzinger AD, Posthuma D. Genomic relationships, novel loci, and pleiotropic mechanisms across eight psychiatric disorders. Cell. 2019;179(7):1469-82.

Lehrl S, Merz J, Burkhard G, Fischer B. Mehrfach-wortschatz-intelligenztest MWT-B. Balingen: Spitta Verlag; 2005.

Leonard CJ, Kaiser ST, Robinson BM, Kappenman ES, Hahn B, Gold JM, Luck SJ. Toward the neural mechanisms of reduced working memory capacity in schizophrenia. Cereb Cortex. 2013;23(7):1582-92.

Leonard CJ, Robinson BM, Hahn B, Luck SJ, Gold JM. Altered spatial profile of distraction in people with schizophrenia. J Abnorm Psychol. 2017;126(8):1077-86.

Lewandowski K, Cohen B, Öngur D. Evolution of neuropsychological dysfunction during the course of schizophrenia and bipolar disorder. Psychol Med. 2011:41(2):225-41. 
Linden DE, Bittner RA, Muckli L, Waltz JA, Kriegeskorte N, Goebel R, Singer W, Munk MH. Cortical capacity constraints for visual working memory: dissociation of fMRI load effects in a fronto-parietal network. Neuroimage. 2003;20(3):1518-30

Luck SJ, Gold JM. The construct of attention in schizophrenia. Biol Psychiatry. 2008;64(1):34-9.

Luck SJ, Vogel EK. Visual working memory capacity: from psychophysics and neurobiology to individual differences. Trends Cogn Sci. 2013;17(8):391-400.

Luck SJ, Hahn B, Leonard CJ, Gold JM. The hyperfocusing hypothesis: A new account of cognitive dysfunction in Schizophrenia. Schizophr Bull. 2019a;45(5):991-1000.

Luck SJ, Leonard CJ, Hahn B, Gold JM. Is Attentional Filtering Impaired in Schizophrenia? Schizophr Bull. 2019b;45(5):1001-11.

Luck SJ, Vogel EK. The capacity of visual working memory for features and conjunctions. Nature. 1997;390(6657):279-81.

Maj M, Pirozzi R, Formicola AM, Bartoli L, Bucci P. Reliability and validity of the DSM-IV diagnostic category of schizoaffective disorder: preliminary data. J Affect Disord. 2000;57(1-3):95-8.

Martínez-Arán A, Vieta E, Reinares M, Colom F, Torrent C, Sánchez-Moreno J, Benabarre A, Goikolea JM, Comes M, Salamero M. Cognitive function across manic or hypomanic, depressed, and euthymic states in bipolar disorder. Am J Psychiatry. 2004;161(2):262-70.

Mayer JS, Fukuda K, Vogel EK, Park S. Impaired contingent attentional capture predicts reduced working memory capacity in schizophrenia. PLoS ONE. 2012;7(11):e48586.

Mayer JS, Park S. Working memory encoding and false memory in schizophrenia and bipolar disorder in a spatial delayed response task. J Abnorm Psychol. 2012;121(3):784.

Mayer JS, Stäblein M, Oertel-Knöchel V, Fiebach CJ. Functional Dissociation of Confident and Not-Confident Errors in the Spatial Delayed Response Task Demonstrates Impairments in Working Memory Encoding and Maintenance in Schizophrenia. Frontiers in psychiatry. 2018;9:202.

$\mathrm{McNab}$ F, Klingberg T. Prefrontal cortex and basal ganglia control access to working memory. Nat Neurosci. 2008;11(1):103.

Miller GA. The magical number seven, plus or minus two: Some limits on our capacity for processing information. Psychol Rev. 1956;63(2):81.

Millett C, Perez-Rodriguez M, Shanahan M, Larsen E, Yamamoto H, Bukowski C, Fichorova R, Burdick K. C-reactive protein is associated with cognitive performance in a large cohort of euthymic patients with bipolar disorder. Mol Psychiatry. 2019;22:1-10.

Miskowiak KW, Burdick K, Martinez-Aran A, Bonnin C, Bowie C, Carvalho A, Gallagher P, Lafer B, López-Jaramillo C, Sumiyoshi T. Assessing and addressing cognitive impairment in bipolar disorder: the International Society for Bipolar Disorders Targeting Cognition Task Force recommendations for clinicians. Bipolar Disord. 2018;20(3):184-94.

Montgomery SA, Åsberg M. A new depression scale designed to be sensitive to change. Br J Psychiatry. 1979;134(4):382-9.

Oertel-Knöchel V, Bittner RA, Knöchel C, Prvulovic D, Hampel H. Discovery and development of integrative biological markers for schizophrenia. Prog Neurobiol. 2011;95(4):686-702.

Oldfield RC. The assessment and analysis of handedness: the Edinburgh inventory. Neuropsychologia. 1971;9(1):97-113.

Owen MJ, O'Donovan MC. Schizophrenia and the neurodevelopmental continuum: evidence from genomics. World Psychiatry. 2017;16(3):227-35.

Pashler H. Familiarity and visual change detection. Percept Psychophys. 1988;44(4):369-78.

Pearlson GD. Etiologic, phenomenologic, and endophenotypic overlap of schizophrenia and bipolar disorder. Annu Rev Clin Psychol. 2015;11:251-81.

Perry A, Roberts G, Mitchell PB, Breakspear M. Connectomics of bipolar disorder: a critical review, and evidence for dynamic instabilities within interoceptive networks. Mol Psychiatry. 2019;24(9):1296-318.

Peters B, Rahm B, Czoschke S, Barnes C, Kaiser J, Bledowski C. Sequential whole report accesses different states in visual working memory. J Exp Psychol Learn Mem Cogn. 2018;44(4):588-603.
Reilly JL, Harris MS, Keshavan MS, Sweeney JA. Adverse effects of risperidone on spatial working memory in first-episode schizophrenia. Arch Gen Psychiatry. 2006;63(11):1189-97.

Reilly JL, Sweeney JA. Generalized and specific neurocognitive deficits in psychotic disorders: utility for evaluating pharmacological treatment effects and as intermediate phenotypes for gene discovery. Schizophr Bull. 2014;40(3):516-22.

Rouder JN, Morey RD, Morey CC, Cowan N. How to measure working memory capacity in the change detection paradigm. Psychon Bull Rev. 2011;18(2):324-30.

Saß H, Wittchen H-U, Zaudig M, Houben I. Dsm-iv-tr. Hogrefe, Göttingen: Diagnostische Kriterien; 2003.

Schretlen DJ, Cascella NG, Meyer SM, Kingery LR, Testa SM, Munro CA, Pulver AE, Rivkin P, Rao VA, Diaz-Asper CM. Neuropsychological functioning in bipolar disorder and schizophrenia. Biol Psychiatry. 2007;62(2):179-86.

Senturk V, Goker C, Bilgic A, Olmez S, Tugcu H, Oncu B, Cem Atbasoglu E. Impaired verbal memory and otherwise spared cognition in remitted bipolar patients on monotherapy with lithium or valproate. Bipolar Disord. 2007;9:136-44.

Stephane M, Pellizzer G. The dynamic architecture of working memory in schizophrenia. Schizophr Res. 2007;92(1-3):160-7.

Tek C, Gold J, Blaxton T, Wilk C, McMahon RP, Buchanan RW. Visual perceptual and working memory impairments in schizophrenia. Arch Gen Psychiatry. 2002;59(2):146-53.

Thompson JM, Gray JM, Hughes JH, Watson S, Young AH, Nicol Ferrier I. Impaired working memory monitoring in euthymic bipolar patients. Bipolar Disord. 2007;9(5):478-89.

Todd JJ, Marois R. Capacity limit of visual short-term memory in human posterior parietal cortex. Nature. 2004;428(6984):751.

Townsend J, Bookheimer SY, Foland-Ross LC, Sugar CA, Altshuler LL. fMRI abnormalities in dorsolateral prefrontal cortex during a working memory task in manic, euthymic and depressed bipolar subjects. Psychiatry Res Neuroimag. 2010;182(1):22-9.

Unsworth N, Fukuda K, Awh E, Vogel EK. Working memory and fluid intelligence: capacity, attention control, and secondary memory retrieval. Cogn Psychol. 2014;71:1-26.

Vogel EK, Machizawa MG. Neural activity predicts individual differences in visual working memory capacity. Nature. 2004;428(6984):748-51.

Vogel EK, McCollough AW, Machizawa MG. Neural measures reveal individual differences in controlling access to working memory. Nature. 2005;438(7067):500.

Vöhringer PA, Barroilhet S, Amerio A, Reale ML, Vergne D, Alvear KP, Ghaemi SN. Cognitive impairment in bipolar disorder and schizophrenia: a systematic review. Front Psychiatry. 2013:4:87.

Volkert J, Kopf J, Kazmaier J, Glaser F, Zierhut K, Schiele M, Kittel-Schneider S, Reif A. Evidence for cognitive subgroups in bipolar disorder and the influence of subclinical depression and sleep disturbances. Eur Neuropsychopharmacol. 2015;25(2):192-202.

Wheeler ME, Treisman AM. Binding in short-term visual memory. J Exp Psychol Gen. 2002;131(1):48.

Wright AA, Katz JS, Magnotti J, Elmore LC, Babb S. Testing pigeon memory in a change detection task. Psychon Bull Rev. 2010;17(2):243-9.

Xu G, Lin K, Rao D, Dang Y, Ouyang H, Guo Y, Ma J, Chen J. Neuropsychological performance in bipolar I, bipolar II and unipolar depression patients: a longitudinal, naturalistic study. J Affect Disord. 2012;136(3):328-39.

Xu Z, Adam K, Fang X, Vogel E. The reliability and stability of visual working memory capacity. Behav Res Methods. 2018;50(2):576-88.

Young RC, Biggs JT, Ziegler VE, Meyer DA. A rating scale for mania: reliability, validity and sensitivity. Br J Psychiatry. 1978;133(5):429-35.

\section{Publisher's Note}

Springer Nature remains neutral with regard to jurisdictional claims in published maps and institutional affiliations. 